\title{
Characteristics of attempted suicides seen in emergency-care settings of general hospitals in eight low- and middle-income countries
}

\author{
ALEXANDRA FLEISCHMANN ${ }^{1}$, JOSÉ M. BERTOLOTE ${ }^{*}$, DIEGO De LEO ${ }^{2}$, \\ NEURY BOTEGA ${ }^{3}$, MICHAEL PHILLIPS ${ }^{4}$, MERIKE SISASK ${ }^{5}$, \\ LAKSHMI VIJAYAKUMAR ${ }^{6}$, KAZEM MALAKOUTI ${ }^{7}$, LOURENS SCHLEBUSCH ${ }^{8}$, \\ DAMANI DE SILVA ${ }^{9}$, VAN TUONG NGUYEN ${ }^{10}$ AND DANUTA WASSERMAN ${ }^{11}$ \\ ${ }^{1}$ Department of Mental Health and Substance Abuse, World Health Organization, Geneva, Switzerland; \\ ${ }^{2}$ Australian Institute for Suicide Research and Prevention, Griffith University, Brisbane, Queensland, Australia; \\ ${ }^{3}$ Department of Psychiatry, FCM - UNICAMP, Campinas, Brazil ; ${ }^{4}$ Beijing Suicide Research and Prevention \\ Center, Beijing Hui Long Guan Hospital, Beijing, People's Republic of China $;{ }^{5}$ Estonian-Swedish Mental \\ Health and Suicidology Institute, Estonian Center of Behavioral and Health Sciences, Tallinn, Estonia; \\ ${ }^{6}$ Department of Psychiatry, Voluntary Health Services \& SNEHA, Kotturpuram, Chennai, India; \\ ${ }^{7}$ Tehran Psychiatric Institute, Mental Health Research Centre, Tehran, Islamic Republic of Iran; \\ ${ }^{8}$ Department of Behavioural Medicine, School of Family and Public Health Medicine, Faculty of Health \\ Sciences, Nelson R. Mandela School of Medicine, University of KwaZulu-Natal, Durban, South Africa; \\ ${ }^{9}$ Department of Psychological Medicine, Faculty of Medicine, University of Colombo, Sri Lanka; \\ ${ }^{10}$ Hanoi Medical University, Hanoi, Viet Nam; ${ }^{11}$ National and Stockholm County Centre for Suicide Research \\ and Prevention of Mental Ill-Health (NASP), Department of Public Health Sciences, Karolinska Institute \\ and Swedish National Institute of Psychosocial Medicine, Stockholm, Sweden
}

\begin{abstract}
Background. The objective was to describe patients presenting themselves at emergency-care settings following a suicide attempt in eight culturally different sites [Campinas (Brazil), Chennai (India), Colombo (Sri Lanka), Durban (South Africa), Hanoi (Viet Nam), Karaj (Iran), Tallinn (Estonia), and Yuncheng, (China)].
\end{abstract}

Method. Subjects seen for suicide attempts, as identified by the medical staff in the emergency units of 18 collaborating hospitals were asked to participate in a 45-minute structured interview administered by trained health personnel after the patient was medically stable.

Results. Self-poisoning was the main method of attempting suicide in all eight sites. Self-poisoning by pesticides played a particularly important role in Yuncheng $(71.6 \%$ females, $61.5 \%$ males), in Colombo (43.2\% males, $19 \cdot 6 \%$ females), and in Chennai (33.8\% males, $23 \cdot 8 \%$ females). The suicide attempt resulted in danger to life in the majority of patients in Yuncheng and in Chennai (over 65\%). In four of the eight sites less than one-third of subjects received any type of referral for follow-up evaluation or care.

Conclusions. Action for the prevention of suicide attempts can be started immediately in the sites investigated by addressing the one most important method of attempted suicide, namely selfpoisoning. Regulations for the access to drugs, medicaments, pesticides, and other toxic substances need to be improved and revised regulations must be implemented by integrating the efforts of different sectors, such as health, agriculture, education, and justice. The care of patients who attempt suicide needs to include routine psychiatric and psychosocial assessment and systematic referral to professional services after discharge.

\footnotetext{
* Address for correspondence: Dr José M. Bertolote, Department of Mental Health and Substance Abuse, World Health Organization, CH-1211, Geneva 27, Switzerland.

(Email: bertolotej@who.int)
} 


\section{INTRODUCTION}

Suicide is not only a global and personal tragedy, but also a major public health problem. In 2002, it was estimated that 877000 lives were lost due to suicide (WHO, 2003). Suicide occurs in both developed and developing countries, in all age groups. For the past few decades the global picture has been one of rising trends, particularly among younger age groups, where suicide is among the five leading causes of death for both sexes.

Depending on the location, suicide attempts can be up to 10-40 times more frequent than completed suicides (Schmidtke et al. 1996). In many countries, suicide attempts are one of the main reasons for hospital emergency treatment of young people, putting a heavy burden on health-care systems. The majority of individuals who attempt suicide tend to be adolescents and young adults, and together they form a pool from which many future suicides emerge (United Nations Department for Policy Coordination and Sustainable Development, 1996; Hultén et al. 2000).

Whereas many WHO Member States report on mortality, including suicide mortality, no official or systematically collected statistics on suicide attempts exist on a national basis. The WHO/EURO multicentre study on suicidal behaviour, monitored attempted suicides treated at 25 health facilities in 19 European countries, including Israel and Turkey (Platt et al. 1992; Schmidtke et al. 2004) between 1989 and 1992. However, the information thus obtained cannot be construed as representing the respective 'national reality'.

In 2000, the WHO launched the multisite intervention study on suicidal behaviours (SUPRE-MISS) which aimed to increase knowledge about suicidal behaviours and about the effectiveness of interventions for suicide attempters in culturally diverse places around the world.

SUPRE-MISS has three components: (i) a randomized clinical trial to evaluate treatment strategies for suicide attempters resuscitated in emergency settings in defined catchment areas; (ii) a community survey to identify suicidal ideation and behaviour in the same catchment areas; and (iii) a qualitative community description of the basic socio-cultural characteristics of the target communities.

This paper describes the characteristics of the suicide attempters of the intake component (i). The majority of these participated in the randomized clinical controlled trial.

\section{METHOD}

\section{The emergency-care departments}

The study was carried out in one or more emergency-care departments of the participating sites. In Campinas (Brazil), it was Hospital das Clinicas, Universidade Estadual de Campinas. In Chennai (India), the Government Royapettah Hospital. In Colombo (Sri Lanka), the acute care wards of the National Hospital Sri Lanka. In Durban (South Africa), the Addington, King Edward VIII, RK Khan, and Prince Mshiyeni Memorial hospitals were involved in the study. In Hanoi (Viet Nam), the Bach Mai, Dong Da, Saint Pault, and Thanh Nhan hospitals participated. In Karaj (The Islamic Republic of Iran), the Emam, Madani, Ghaem and Rajaee hospitals were involved. In Tallinn (Estonia), the North Estonian Regional Hospital (the Tallinn Mustamae Hospital and the Tallinn Psychiatric Clinic) participated. In Yuncheng (People's Republic of China), it was the Yuncheng County Hospital. These hospitals served the respective catchment area of the participating sites which were mostly urban, except for Yuncheng which was rural.

\section{Subjects}

All suicide attempters identified between January 2002 and January 2004 (in Hanoi up to April 2004) in emergency-care settings by medical staff within a catchment area with a population of at least 250000 in eight countries were invited to participate in the study. Those who agreed, filled in a consent form and were administered the detailed intake interview. A total of 4314 subjects were included. Their distribution by age, sex and site is given in Table 1.

\section{Interviewing}

At each site 2-12 psychiatrists, medical doctors, psychologists and, in one instance, psychiatric nurses were trained to administer the intake 
Table 1. Sex and age of suicide attempters at emergency care departments of SUPRE-MISS sites

\begin{tabular}{|c|c|c|c|c|c|c|c|c|c|c|c|c|c|c|c|c|}
\hline & \multicolumn{2}{|c|}{$\begin{array}{c}\text { Campinas } \\
(n=162)\end{array}$} & \multicolumn{2}{|c|}{$\begin{array}{l}\text { Chennai } \\
(n=680)\end{array}$} & \multicolumn{2}{|c|}{$\begin{array}{l}\text { Colombo } \\
(n=1067)\end{array}$} & \multicolumn{2}{|c|}{$\begin{array}{c}\text { Durban } \\
(n=570)\end{array}$} & \multicolumn{2}{|c|}{$\begin{array}{c}\text { Hanoi } \\
(n=301)\end{array}$} & \multicolumn{2}{|c|}{$\begin{array}{c}\text { Karaj } \\
(n=945)\end{array}$} & \multicolumn{2}{|c|}{$\begin{array}{c}\text { Tallinn } \\
(n=469)\end{array}$} & \multicolumn{2}{|c|}{$\begin{array}{l}\text { Yuncheng } \\
(n=120)\end{array}$} \\
\hline & M & $\mathrm{F}$ & M & $\mathrm{F}$ & M & $\mathrm{F}$ & M & $\mathrm{F}$ & M & $\mathrm{F}$ & M & $\mathrm{F}$ & M & $\mathrm{F}$ & M & $\mathrm{F}$ \\
\hline Sex $(\%$, rounded $)$ & 35 & 64 & 49 & 51 & 44 & 56 & 27 & 71 & 29 & 71 & 42 & 58 & 34 & 66 & 33 & 68 \\
\hline Age (years) (median) & 29 & 30 & 25 & 22 & 25 & 22 & 26 & 21 & 24 & 23 & 23 & 22 & 29 & 30 & 33 & 30 \\
\hline
\end{tabular}

M, Male; F, female.

interview. The interviews were conducted faceto-face and took place at the emergency-care departments. Suicide attempters were identified by the medical staff in the emergency rooms and interviewed once medically stable, at most 3 days after the emergency room admission.

\section{Instrument}

The questionnaire, based on the European Parasuicide Study Interview Schedule (EPSIS), (Kerkhof et al. 1999), of the WHO/EURO multicentre study on suicidal behaviour was translated and pilot-tested in each country. It covered a detailed intake part comprising the method of the suicide attempt, physical consequences, the type of care and referral as determined by the medical staff, as well as sociodemographic information. A series of other variables was also answered, the results of which are not reported here (WHO, 2002a).

\section{RESULTS}

\section{The intake of subjects}

An attempt was made to include all suicide attempters seen at the emergency-care departments. However, inadequate recording of emergency room visits, intentional misreporting of suicides as accidental by patients and family members, failure of the emergency room staff to notify research staff, and rapid departure from the emergency rooms of patients (before the research staff could arrive) made it difficult to include all eligible patients in the intake, to enrol them eventually and, in some instances, even to make an accurate assessment of the total number of suicide attempters coming to the emergency-care units. Given the nature of these reasons, it is impossible to both estimate the number of these 'losses' and identify means of avoiding them.
In Karaj $(n=945)$ and Hanoi $(n=301)$ all suicide attempters identified in the emergencycare departments over the specified period participated in the intake evaluation. In Campinas $(n=162)$, Durban $(n=570)$ and Colombo $(n=1067)$ almost all subjects completed the intake interview. However, the total number of suicide attempters seen at the emergency-care department was not known, because it was suspected that a small (unknown) number of cases was not notified by the emergency departments to the researchers: the subjects could have been admitted directly to a psychiatric unit without being treated in the emergency department or the subjects might have left before the research team could meet them. Also, in Colombo almost all selfpoisoning and surgically serious self-injury patients who were admitted participated in the intake evaluation, but the number of suicide attempts that were not seen at the acute care wards was unknown.

In Chennai 680 out of $1691(40 \%)$, in Tallinn 469 out of $884(53 \%)$ and in Yuncheng 120 out of $194(62 \%)$ suicide attempters seen in the emergency-care departments participated in the intake interview. Of those who did not participate, only sex and age are known; the majority of those not interviewed precipitously left the emergency-care department before the researchers arrived to conduct the interview.

\section{Sociodemographic characteristics}

In all sites, more female than male suicide attempters presented themselves at the emergency-care departments ranging from $51.3 \%$ (Chennai) to $71 \cdot 2 \%$ (Durban). Three persons (one in Campinas, two in Durban) indicated themselves to be transsexual. Overall, the patients were young. The median age among females ranged from 21 years (Durban) to 30 


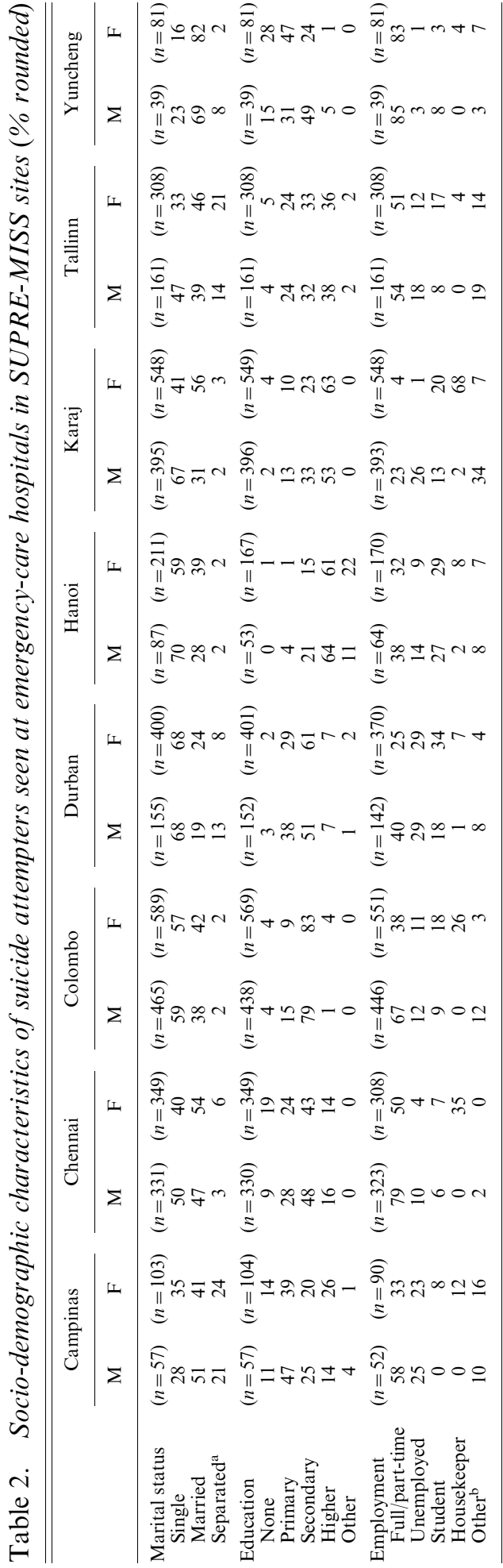

years (Campinas and Yuncheng) and from 23 (Karaj) to 33 years (Yuncheng) among males. Campinas and Tallinn were the only sites where the median age of females was higher than for males (Table 1).

In six of the eight countries male attempters were more likely to be single than married, and in four of the eight countries female attempters were more likely to be single than married. In all sites, except for Campinas, female attempters were more likely to be married than male attempters (Table 2). Divorce was common among suicide attempters in Campinas $(17.5 \%$ males, $22.3 \%$ females) and in Tallinn $(13.0 \%$ males, $14.6 \%$ females). In all sites, except for Campinas, women were more frequently married than men (Table 2).

With the exception of Yuncheng (where men had a higher educational attainment than women) the educational achievement of male and female suicide attempters was similar (Table 2).

Except for Durban and Karaj the majority of subjects were employed full-time or part-time at the time of admission to the emergency-care departments. The other common employment categories were 'unemployed', 'housekeeper' and 'full-time student' (Table 2).

\section{Main method of the suicide attempt according to ICD-10 codes}

Self-poisoning - which accounted for $69-98 \%$ of all cases - was the predominant method of suicide attempts seen in the emergency departments at all sites, far exceeding the other methods of 'cutting', 'hanging', etc. (Table 3). In most cases self-poisoning involved the ingestion of pesticides or medications. In Yuncheng pesticide ingestion was the most frequently reported method among both men $(61.5 \%)$ and women $(71.6 \%)$; in Colombo and Chennai it was the most commonly used method in men $(43.2 \%$ and $33.8 \%$ respectively) and the second most commonly used method in women (19.6\% and $23.8 \%$ respectively); it was also an important method in Campinas and Hanoi.

More than one method, i.e. a combination of methods, was rarely applied. The one exception was in Tallinn, where $10.7 \%$ of the suicide attempters combined self-poisoning by alcohol with another method. 
Table 3. Main method of attempted suicide according to ICD-10 codes in SUPRE-MISS sites (\% rounded)

\begin{tabular}{|c|c|c|c|c|c|c|c|c|c|c|c|c|c|c|c|c|}
\hline & \multicolumn{2}{|c|}{ Campinas } & \multicolumn{2}{|c|}{ Chennai } & \multicolumn{2}{|c|}{ Colombo } & \multicolumn{2}{|c|}{ Durban } & \multicolumn{2}{|c|}{ Hanoi } & \multicolumn{2}{|c|}{ Karaj } & \multicolumn{2}{|c|}{ Tallinn } & \multicolumn{2}{|c|}{ Yuncheng } \\
\hline & $\underset{(n=56)}{\mathrm{M}}$ & $\underset{(n=104)}{\mathrm{F}}$ & $\underset{(n=331)}{\mathrm{M}}$ & $\begin{array}{c}\mathrm{F} \\
(n=349)\end{array}$ & $\underset{(n=465)}{\mathrm{M}}$ & $\begin{array}{c}\mathrm{F} \\
(n=586)\end{array}$ & $\underset{(n=153)}{\mathrm{M}}$ & $\begin{array}{c}\mathrm{F} \\
(n=395)\end{array}$ & $\underset{(n=83)}{\mathrm{M}}$ & $\begin{array}{c}\mathrm{F} \\
(n=205)\end{array}$ & $\begin{array}{c}\text { M } \\
(n=395)\end{array}$ & $\begin{array}{c}\mathrm{F} \\
(n=546)\end{array}$ & $\underset{(n=161)}{\mathrm{M}}$ & $\begin{array}{c}\mathrm{F} \\
(n=308)\end{array}$ & $\underset{(n=39)}{\mathrm{M}}$ & $\underset{(n=81}{\mathrm{F}}$ \\
\hline \multicolumn{17}{|l|}{ Self-poisoning } \\
\hline $\begin{array}{l}\text { Non-opioid analgesics } \\
\text { and antipyretics }\end{array}$ & 0 & 2 & 1 & 5 & 14 & 27 & 48 & 54 & 52 & 75 & 9 & 13 & 11 & 22 & 0 & 0 \\
\hline $\begin{array}{l}\text { Anti-epileptic and } \\
\text { sedative-hypnotic drugs }\end{array}$ & 39 & 58 & 8 & 12 & 8 & 11 & 10 & 6 & 4 & 10 & 51 & 47 & 50 & 59 & 31 & 21 \\
\hline Other medicaments & 2 & 6 & 33 & 40 & 8 & 16 & 9 & 17 & 2 & 2 & 11 & 13 & 3 & 2 & 0 & 3 \\
\hline Alcohol & 0 & 2 & 0 & 0 & 1 & 0 & 0 & 0 & 0 & 0 & 1 & 1 & 2 & 1 & 0 & 0 \\
\hline Pesticides & 18 & 7 & 34 & 24 & 43 & 20 & 2 & 3 & 16 & 5 & 3 & 2 & 1 & 0 & 62 & 72 \\
\hline Other ${ }^{\mathrm{a}}$ & 13 & 5 & 21 & 17 & 17 & 19 & 17 & 16 & 16 & 5 & 16 & 21 & 4 & 3 & 5 & 2 \\
\hline All Poisonings & 72 & 79 & 97 & 98 & 91 & 93 & 86 & 96 & 89 & 98 & 91 & 96 & 69 & 88 & 97 & 98 \\
\hline Hanging and suffocation & 2 & 6 & 3 & 1 & 2 & 1 & 5 & 2 & 7 & 2 & 1 & 0 & 7 & 5 & 3 & 3 \\
\hline $\begin{array}{l}\text { Cutting with sharp or } \\
\text { blunt object }\end{array}$ & 18 & 4 & 0 & 0 & 2 & 1 & 4 & 2 & 2 & 0 & 6 & 2 & 20 & 6 & 0 & 0 \\
\hline Other ${ }^{\mathrm{b}}$ & 9 & 12 & 0 & 1 & 6 & 6 & 6 & 1 & 1 & 1 & 3 & 2 & 4 & 2 & 0 & 0 \\
\hline
\end{tabular}

M, Male; F, female.

a Self-poisoning other, including: narcotics and psychodysleptics, not elsewhere classified; other drugs acting on the autonomic nervous system; organic solvents and halogenated hydrocarbons and their vapours; other gases and vapours; other and unspecified chemicals and noxious substances.

Other, including drowning; all firearms; smoke, fire, steam and hot objects; jumping from a high place; jumping or lying before a moving object; other specified means; unspecified means.

Table 4. Consequences of the attempted suicide and care in the SUPRE-MISS sites (\% rounded)

\begin{tabular}{|c|c|c|c|c|c|c|c|c|c|c|c|c|c|c|c|c|}
\hline & \multicolumn{2}{|c|}{ Campinas } & \multicolumn{2}{|c|}{ Chennai } & \multicolumn{2}{|c|}{ Colombo } & \multicolumn{2}{|c|}{ Durban } & \multicolumn{2}{|c|}{ Hanoi } & \multicolumn{2}{|c|}{ Karaj } & \multicolumn{2}{|c|}{ Tallinn } & \multicolumn{2}{|c|}{ Yuncheng } \\
\hline & M & $\mathrm{F}$ & M & $\mathrm{F}$ & M & $\mathrm{F}$ & M & $\mathrm{F}$ & M & $\mathrm{F}$ & M & $\mathrm{F}$ & M & $\mathrm{F}$ & M & $\mathrm{F}$ \\
\hline $\begin{array}{l}\text { Physical } \\
\text { consequences }\end{array}$ & $(n=57)$ & $(n=102)$ & $(n=331)$ & $(n=349)$ & $(n=472)$ & $(n=587)$ & $(n=153)$ & $(n=402)$ & $(n=88)$ & $(n=213)$ & $(n=396)$ & $(n=549)$ & $(n=160)$ & $(n=308)$ & $(n=39)$ & $(n=81)$ \\
\hline None & 18 & 28 & 0 & 0 & 16 & 20 & 20 & 18 & 6 & 8 & 11 & 12 & 3 & 3 & 0 & 0 \\
\hline $\operatorname{Mix}^{\mathrm{a}}$ & 30 & 35 & 25 & 34 & 47 & 52 & 77 & 76 & 65 & 81 & 74 & 77 & 53 & 59 & 33 & 20 \\
\hline Yes $^{\mathrm{b}}$ & 53 & 37 & 75 & 66 & 37 & 28 & 4 & 6 & 30 & 11 & 15 & 11 & 44 & 37 & 67 & 80 \\
\hline Referral & $(n=28)$ & $(n=43)$ & $(n=331)$ & $(n=346)$ & $(n=424)$ & $(n=560)$ & $(n=133)$ & $(n=357)$ & $(n=88)$ & $(n=213)$ & $(n=392)$ & $(n=553)$ & $(n=141)$ & $(n=274)$ & $(n=39)$ & $(n=81)$ \\
\hline None & 7 & 9 & 98 & 98 & 62 & 67 & 12 & 12 & 74 & 82 & 48 & 47 & 16 & 28 & 97 & 99 \\
\hline General health care & 68 & 79 & 0 & 0 & 9 & 7 & 2 & 4 & 7 & 5 & 40 & 42 & 28 & 20 & 0 & 0 \\
\hline Psychiatric care & 21 & 5 & 2 & 2 & 30 & 26 & 86 & 84 & 19 & 13 & 6 & 5 & 55 & 50 & 3 & 1 \\
\hline Private & 4 & 7 & 0 & 0 & 0 & 0 & 1 & 1 & 0 & 0 & 6 & 6 & 1 & 2 & 0 & 0 \\
\hline
\end{tabular}

M, Male; F, female.

a Mix, 'Medical attention/surgery required, but no danger to life. 


\section{Consequences of the attempted suicide and care}

The suicide attempt resulted in physical consequences and danger to life (assessed by the medical staff and understood as an indication of the clinical severity of the attempt) in more than $50 \%$ of the cases in Yuncheng $(80.2 \%$ of the females and $66.7 \%$ of the males), Chennai (74.6\% of the males and $65.9 \%$ of the females) and Campinas $(52.6 \%$ of the males). In the remaining sites, most subjects required a combination of medical attention or surgery, but there was no danger to life (Table 4).

With regards to the type of care, transfer to a psychiatric institution ranged from $0 \%$ to $34 \%$; in most of the sites it was very low (between $0 \%$ and $8 \%$ of the cases), with the exception of Campinas (23.9\% for women) and Tallinn (34\% for men).

Practically no referral to any professional service was made in Yuncheng for both men $(97.4 \%)$ and women $(98.8 \%)$ and in Chennai ( $97.6 \%$ for men, $98.3 \%$ for women), which reflects the non-existence of eligible referral services in these locations. In Hanoi, Colombo and Karaj the amount of non-referral was equally dominant among both men and women (46.5-81.7\%). In Campinas referral was primarily made to a general health-care or primary health-care centre $(67 \cdot 9-79 \cdot 1 \%$, both sexes). In Durban and Tallinn, the patients were mainly sent to a psychiatric out-patient clinic $(50 \cdot 4-85 \cdot 7 \%$, both sexes). In four of the eight sites less than one-third of subjects received any type of referral for follow-up evaluation or care (Table 4).

A separate question regarding the acceptance of an offer of professional care, which was not linked to the referral, was answered positively by the majority of subjects, i.e. they would accept to go to the consultation offered. Refusals were strongest in Colombo (up to $38.5 \%$ for females).

\section{DISCUSSION}

This is the first study to provide detailed information on cases of suicide attempts from a wide range of developing countries. For several of the participating countries, it is the first data on attempted suicides ever collected or published both in national and international periodicals.
The situation in virtually all participating emergency settings is such that suicide attempts are not recorded on a routine basis, resulting in a lack of data to estimate rates of suicide attempts. An effort was made to collect for the first time this basic intake information from all suicide attempters in the emergency-care settings.

Despite careful preparations, in some sites a few subjects managed to slip through. In some sites the number was not known (although believed to be very small), in other sites at least sex and age of those not completing the intake were known (allowing a comparison of those who did and did not participate in the intake), and in a third group of sites all subjects were part of the intake. Future thorough analyses specifically addressing sample issues will provide a sense of how representative the reported cases are.

This sample of attempted suicides identified in emergency rooms of hospitals in eight developing countries is, like those identified in developed countries (Diekstra, 1993; Schmidtke et al. 1996; Latha et al. 1996; Thanh et al. 2005), primarily composed of young adults. The male : female gender ratio in the eight countries ranged from $1: 1 \cdot 1$ to $1: 2.6$ which is similar to that reported in the $\mathrm{WHO} / \mathrm{EURO}$ multicentre study [1:0.7 to $1: 2.3$ (Schmidtke et al. 2004)]. Unlike reports from developed countries (Löhr \& Schmidtke, 2004), a high proportion of the subjects in this study were married at the time of their attempt, suggesting that marriage is not a strong protective factor for suicide attempt in developing countries (WHO, 2002b).

Similar to other countries, self-poisoning is the most common method of suicide attempt, and the ingestion of pesticides, medications or other poisons accounted for $69-98 \%$ of all suicide attempts identified in the emergencycare units of the eight sites included in the study. Nevertheless, pesticides are a more common method of self-poisoning in developing countries, particularly in China, India, and Sri Lanka.

These findings strongly support earlier reports on the role of pesticide poisoning in attempted and completed suicide in developing countries (Latha et al. 1996; Eddleston, 2000; Phillips \& Li, 2002; Phillips et al. 2002; Gunnell \& Eddleston, 2003; Eddleston \& Phillips, 2004). 
It has been shown repeatedly that restricting the access to and the availability of the prevailing method can be effective in reducing the frequency of suicide attempts (Bowles, 1995; Roberts et al. 2003).

This result calls for immediate action on this issue, where it is relevant, including the analysis of regulations, distribution, availability, access, and packaging of these substances, and for prompt intervention after the intoxication, with local emphasis on the most used substance, e.g. pesticides in these Asian countries.

Another important finding was the relative lack of professional services for referral of suicide attempters. This results in a situation where the care is limited to somatic symptoms only. Even in those places where psychological or psychiatric services were available, psychiatric assessment and referral were not delivered in a systematic way or as part of a routine which is in agreement with a study from Europe regarding young suicide attempters (Hultén et al. 2000). In these places, the current situation leaves plenty of room for improvement of the health services.

Accurate, standardized information on the rates and characteristics of medically treated suicide attempts is essential to the development and evaluation of preventive services, however, the emergency departments of hospitals in both developed and less-developed countries are not currently able to collect this information. Our study has highlighted several of the difficulties that need to be overcome to rectify this problem: incomplete or inaccurate registration of persons seen in emergency departments; patients and family members intentionally misreporting the cause of the attempted suicide injury or absconding from the emergency department as soon as possible to avoid stigma (Wasserman, 2001) and (in some cases) legal sanctions; clinicians not recording routinely suicide attempts as such and, therefore, failing to collect essential information or to provide follow-up referrals, or (in some cases) because they wish to avoid legal proceedings. The magnitude and causes of the problems vary across the countries included in this study, largely due to cultural and socio-economic factors. Rectifying these problems will require substantial legal, administrative and attitudinal changes.

\section{ACKNOWLEDGEMENTS}

The study was funded by the Department of Mental Health and Substance Abuse, World Health Organization, where both first authors are employed. Some field research sites obtained additional funding from the following agencies. Hanoi: Swedish International Cooperation Development Agency (SIDA), Stockholm, Sweden [within the collaboration between the Swedish National and Stockholm County Council's Centre for Suicide Research and Prevention of Mental Ill-Health (NASP) at the Institute for Psychosocial Medicine (IPM) and the Department of Public Health Sciences at the Karolinska Institute and Hanoi Medical University]. Karaj: Iran National Research Center for Medical Sciences, Tehran, Iran. Tallinn: Estonian Health Insurance Fund, Tallinn, Estonia; the Swedish National and Stockholm County Council's Centre for Suicide Research and Prevention of Mental Ill-Health (NASP) at the Institute for Psychosocial Medicine (IPM) and the Department of Public Health Sciences at the Karolinska Institute, Stockholm, Sweden.

\section{DECLARATION OF INTEREST}

None.

\section{REFERENCES}

Bowles, J. R. (1995). An example of a suicide prevention program in a developing country. In Preventive Strategies on Suicide (ed. R. F. W. Diekstra, W. Gulbinat, I. Kienhorst and D. De Leo), pp. 173-206. Brill: Leiden.

Diekstra, R. F. W. (1993). The epidemiology of suicide and parasuicide. Acta Psychiatrica Scandinavica (Suppl.) 371, 9-20.

Eddleston, M. (2000). Patterns and problems of deliberate selfpoisoning in the developing world. QJM Monthly Journal of the Association of Physicians 93, 715-731.

Eddleston, M. \& Phillips, M. R. (2004). Self poisoning with pesticides. British Medical Journal 328, 42-44.

Gunnell, D. \& Eddleston, M. (2003). Suicide by intentional ingestion of pesticides; a continuing tragedy in developing countries. International Journal of Epidemiology 32, 902-909.

Hultén, A., Wasserman, D., Hawton, K., Jiang, G. X., SalanderRenberg, E., Schmidtke, A., Bille-Brahe, U., Bjerke, T., Kerkhof, A., Michel, K. \& Querejeta, I. (2000). Recommended care for young people (15-19 years) after suicide attempts in certain European countries. European Child and Adolescent Psychiatry 9, 100-108.

Kerkhof, A., Bernasco, W., Bille-Brahe, U., Platt, S. \& Schmidtke, A. (1999). European Parasuicide Study Interview Schedule (EPSIS). In Facts and Figures: WHO/EURO (ed. U. Bille-Brahe). WHO Regional Office for Europe: Copenhagen.

Latha, K. S., Bhat, S. M. \& D'Souza, P. (1996). Suicide attempters in a general hospital unit in India: their socio-demographic 
and clinical profile-emphasis on cross-cultural aspects. Acta Psychiatrica Scandinavica 94, 26-30.

Löhr, C. \& Schmidtke, A. (2004). Marital relations of suicide attempters. In Suicidal Behaviour: Theories and Research Findings (ed. D. De Leo, U. Bille-Brahe, A. Kerkhof and A. Schmidtke). Hogrefe \& Huber: Göttingen.

Phillips, M. R. \& Li, X. (2002). Suicide rates in China, 1995-99. Lancet 359, 835-840.

Phillips, M. R., Yang, G., Zhang, Y., Wang, L., Ji, H. \& Zhou, M. (2002). Risk factors for suicide in China: a national case-control psychological autopsy study. Lancet 360, 1728-1736.

Platt, S., Bille-Brahe, U., Kerkhof, A., Schmidtke, A., Bjerke, T., Crepet, P., De Leo, D., Haring, C., Lonnqvist, J., Michel, K., Philippe, A., Pommereau, X., Querejeta, I., Salander-Renberg, E., Temesvary, B., Wasserman, D. \& Sampaio-Faria, J. G. (1992). Parasuicide in Europe: the WHO/EURO multicentre study on parasuicide. I. Introduction and preliminary analysis for 1989. Acta Psychiatrica Scandinavica 85, 97-104.

Roberts, D. M., Karunarathna, A., Buckley, N. A., Manuweera, G., Sheriff, M. H. R. \& Eddleston, M. (2003). Influence of pesticide regulation on acute poisoning deaths in Sri Lanka. Bulletin of the World Health Organization 81, 1-10.

Schmidtke, A., Bille-Brahe, U., De Leo, D. \& Kerkhof, A. (eds). (2004). Suicidal behaviour in Europe: Results from the WHO EURO Multicentre Study on Suicidal Behaviour. Hogrefe \& Huber: Göttingen.
Schmidtke, A., Bille-Brahe, U., De Leo, D., Kerkhof, A., Bjerke, T. Crepet, P., Haring, C., Hawton, K., Lonnqvist, J., Michel, K., Pommereau, X., Querejeta, I., Philipe, I., Salander-Renberg, E., Temesvary, B., Wasserman, D., Fricke, S., Weinacker, B. \& Sampaio-Faria, J. G. (1996). Attempted suicide in Europe: rates, trends and sociodemographic characteristics of suicide attempters during the period 1989-1992. Results of the WHO/EURO Multicentre Study on Parasuicide. Acta Psychiatrica Scandinavica 93, 327-338.

Thanh, H. T. T., Jiang, G. X., Van, T. N., Minh, D. P. T., Rosling, H. \& Wasserman, D. (2005). Attempted suicide in Hanoi, Vietnam. Social Psychiatry and Psychiatric Epidemiology 40, 64-71.

United Nations Department for Policy Coordination and Sustainable Development (1996). Prevention of Suicide. Guidelines for the Formulation and Implementation of National Strategies. United Nations: New York.

Wasserman, D. (2001). Suicide: An Unnecessary Death. Dunitz: London.

WHO (2002a). Multisite Intervention Study on Suicidal Behaviours SUPRE-MISS: Protocol of SUPRE-MISS. World Health Organization: Geneva.

WHO (2002b). World Report on Violence and Health. World Health Organization: Geneva.

WHO (2003). The World Health Report 2003: Shaping the Future. World Health Organization: Geneva. 